\title{
BILANGAN TERHUBUNG PELANGI PADA AMALGAMASI GRAF BERLIAN
}

\author{
Cindy Aisa Putri Noor ${ }^{1 *}$, Karina Ansyelia Mamonto ${ }^{2}$, Widya Eka Pranata ${ }^{3}$ \\ 1,2,3 Jurusan Matematika, Universitas Negeri Gorontalo, Bone Bolango 96119, Indonesia \\ *Penulis Korespondensi. Email: cindy.aisa2010@gmail.com
}

\begin{abstract}
Abstrak
Misalkan $G=(V, E)$ adalah graf terhubung tak trivial. Graf $G$ dikatakan terhubung pelangi jika untuk setiap dua titik $x$ dan $y$ terdapat lintasan pelagi dari $x$ dan $y$. Bilangan terhubung pelangi didefinisikan sebagai minimum $k$ dari pewarnaan $-k$ pelangi sehingga menghasilkan sebuah lintasan pelangi dengan dua sisi bertetangga memiliki warna yang berbeda dan dinotasikan sebagai $r c(G)$. Misalkan t adalah bilangan asli dengan $t \geq 2$ dan misalkan $\left\{G_{i} \mid i \in[1, t]\right\}$ adalah graf terhubung tak trivial dengan setiap $G_{i}$ mempunyai titik tetap $v_{0 i}$, maka amalgamasi untuk graf $G$ dinotasikan dengan $\operatorname{Amal}\left(G_{i}, v_{0 i}, t\right)$. Amalgamasi merupakan salah satu operasi matematika yang terbentuk dengan merekatkan semua graf $G_{i}$ pada titik $v_{0 i}$ dengan titik $v_{0 i}$ merupakan titik terminal. Dalam penelitian ini operan yang digunakan pada operasi amalgamasi adalah graf berlian dengan notasi $\operatorname{Amal}\left(B r_{n}, v, t\right)$ dengan $t \geq 2$.
\end{abstract}

Kata Kunci: Bilangan Terhubung; Pelangi; Amalgamasi; Graf Berlian

\section{Pendahuluan}

Teori graf merupakan cabang ilmu matematika yang mempelajari tentang sifat-sifat graf. Graf merupakan himpunan tak trivial dari pasangan himpunan $(V, E)$, dengan $V$ merupakan himpunan tidak kosong dari titik (vertex) dan $E$ merupakan himpunan sisi (edge) yang menghubungkan sepasang titik dimana $E$ mungkin saja kosong. Pasangan himpunan tersebut dinotasikan dengan $G=(V, E)[1]$.

Seiring berjalannya waktu, teori graf mengalami perkembangan pesat dengan lahirnya cabang-cabang ilmu baru seperti pelabelan graf, penjodohan, bilangan terhubung pelangi, hingga amalgamasi. Amalgamasi merupakan sebuah operasi graf dengan pasangan titik graf $(G, u)$ dan $(H, v)$ yang diperoleh dengan menggabungkan titik $u$ dan $v$ menjadi satu titik [2].

Salah satu cabang ilmu baru dari teori graf adalah bilangan terhubung pelangi yang pertama kali diperkenalkan oleh Chatrand [3]. Bilangan terhubung pelangi merupakan minimum $k$ dari pewarnaan $-k$ pelangi sehingga menghasilkan sebuah lintasan pelangi dengan dua sisi bertetangga memiliki warna yang berbeda. Jika graf $G$ memiliki diameter yang berupa jarak terdekat antara $v_{1}$ dan $v_{2}$ yang dinotasikan dengan $\operatorname{diam}(G)$ dan juga memiliki sisi sebanyak $m$, maka :

$$
\operatorname{diam}(G) \leq r c(G) \leq \operatorname{src}(G) \leq m
$$

Dari penjelasan diatas maka muncullah gagasan untuk melakukan penelitian bilangan terhubung pelangi dengan menggunakan operasi amalgamasi. Adapun operan yang digunakan dalam operasi amalgamasi ini adalah graf berlian dengan titik yang diambil adalah titik $v$ pada graf berlian. Graf berlian merupakan graf dengan $2 n$ titik yang diperoleh dari graf tangga segitiga dengan $2 n-1$ titik dan ditambahkan satu titik dan beberapa sisi tertentu dengan notasi $B r_{n}$ [4].

\section{Metode Penelitian}

Penelitian ini menggunakan metode penelitian studi literatur (library research). Pada penelitian ini dilakukan kajian terhadap buku, textbook, jurnal, dan artikel-artikel ilmiah mengenai amalgamasi dan graf berlian. Adapun langkah-langkah yang dilakukan adalah

1. Mempelajari literatur, 
2. Menggambar bentuk amalgamasi graf berlian,

3. Menentukan pola pewarnaan amalgamasi graf berlian, dan

4. Membuktikan teorema.

\section{Pembahasan}

Graf berlian dinotasikan dengan $B r_{n}$ dengan definisi sisi dan titik sebagai berikut :

$$
\begin{aligned}
& V\left(B r_{n}\right)=\{v\} \cup\left\{v_{i} \mid i \in\{1,2, \ldots, n\}\right\} \cup\left\{u_{i} \mid i \in\{1,2, \ldots n-1\}\right\} \\
& E\left(B r_{n}\right)=\left\{v v_{i} \mid i \in\{1,2, \ldots, n\}\right\} \cup\left\{v_{i} v_{i+1} \mid i \in\{1,2, \ldots, n-1\}\right\} \cup\left\{u_{i} u_{i+1} \mid i \in\{1,2, \ldots, n-2\}\right\} \\
& \cup\left\{u_{i} v_{i} \mid i \in\{1,2, \ldots, n-1\}\right\} \cup\left\{u_{i} v_{i-1} \mid i \in\{1,2, \ldots, n-1\}\right\}
\end{aligned}
$$

Gambar graf berlian $B r_{4}$ dapat dilihat pada Gambar 1.

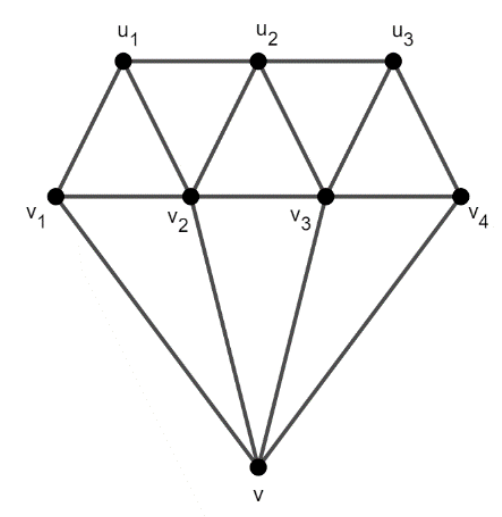

Gambar 1. Graf Berlian $\mathrm{Br}_{4}$

Amalgamasi graf berlian $\left(B r_{n}\right)$ sebanyak $t$ dengan $v$ adalah titik terminal dinotasikan dengan $A m a l\left(B r_{n}, v, t\right)$ dengan $4 \leq n \leq 6 . A m a l\left(B r_{n}, v, t\right)$ memiliki diameter 4 dan didefinisikan sebagai berikut :

$$
\begin{gathered}
V\left(\operatorname{Amal}\left(B r_{n}, v, t\right)\right)=\left\{\begin{array}{lll}
u_{i, j}, & i \in[1, t] & j \in[1, n-1] \\
v_{i, j}, & i \in\{1, t] & j \in[1, n] \\
v &
\end{array}\right. \\
E\left(\operatorname{Amal}\left(B r_{n}, v, t\right)\right)=\left\{\begin{array}{cll}
u_{i, j} u_{i, j+1} ; & i \in[1, t], & j \in[1, n-2] \\
v_{i, j} v_{i, j+1} ; & i \in[1, t], & j \in[1, n-1] \\
u_{i, j} v_{i, j} ; & i \in[1, t], & j \in[1, n-1] \\
u_{i, j} v_{i, j+1} ; & i \in[1, t], & j \in[1, n-1] \\
v_{i, j} v ; & i \in[1, t], & j \in[1, n]
\end{array}\right.
\end{gathered}
$$

\section{Teorema 1}

Misalkan $G \cong \operatorname{Amal}\left(B r_{n}, v, t\right)$ dengan bilangan bulat $4 \leq n \leq 6$ dan $t \geq 2$, maka bilangan terhubung pelangi pada $G$ adalah :

$$
\operatorname{rc}\left(\operatorname{Amal}\left(B r_{n}, v, t\right)\right)=2 t
$$

\section{Bukti}

Untuk $\operatorname{Amal}\left(B r_{n}, v, t\right)$ dengan bilangan bulat $4 \leq n \leq 6$ dan $t \geq 2$ memiliki diameter 4 dan bilangan terhubung pelangi 2t. Karena $\operatorname{rc}\left(\operatorname{Amal}\left(B r_{n}, v, t\right)\right)=2$ dan $t \geq 2$ maka $r c\left(\operatorname{Amal}\left(B r_{n}, v, t\right)\right) \geq 4$, sehingga 
$\operatorname{diam}\left(\operatorname{Amal}\left(B r_{n}, v, t\right)\right) \leq \operatorname{rc}\left(\operatorname{Amal}\left(B r_{n}, v, t\right)\right)$. Definisikan pewarnaan $\quad c: E(G) \rightarrow\{1,2,3, .$.$\} \quad sebagai$ berikut:

$$
\begin{aligned}
& c\left(u_{i, j} u_{i, j+1}\right)=j, \quad \quad \text { untuk } i \in[1, t], j \in[1, n-2] \\
& c\left(v_{i, j} v_{i, j+1}\right)=(j+1) \bmod 2+2 i-3, \text { untuk } i \in[2, t], j \in[1, n-1] \\
& c\left(v_{1, j} v_{1, j+1}\right)=2 t-(j \bmod 2), \quad \quad \operatorname{untuk} j \in[1, n-1] \\
& c\left(v v_{i, j}\right)=2 i-1+\left\lfloor\frac{j}{4}\right\rfloor, \quad \quad \text { untuk } i \in[1, t], j \in[1, n]
\end{aligned}
$$

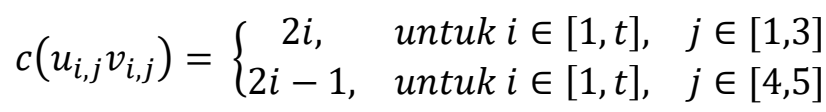

$$
\begin{aligned}
& c\left(u_{i, j} v_{i, j+1}\right)=2 i+1, \quad \quad \text { untuk } i \in[1, t], j \in[1, n], 2 t+1=1
\end{aligned}
$$

Pewarnaan pelangi untuk amalgamasi graf berlian $\operatorname{Amal}\left(B r_{4}, v, 2\right), \operatorname{Amal}\left(B r_{5}, v, 3\right)$, dan $\operatorname{Amal}\left(B r_{6}, v, 4\right)$ berturut-turut dapat dilihat pada gambar 3.2, gambar 3.2, dan gambar 3.4. Untuk menunjukan bahwa terdapat lintasan dari titik $x$ ke titik $y$ di $V\left(\operatorname{Amal}\left(B r_{n}, v, t\right)\right)$ dengan $\operatorname{diam}\left(\operatorname{Amal}\left(B r_{n}, v, t\right)\right)=4$, maka diperoleh lintasan pelangi :

Kasus 1. Untuk $n=4$

Subkasus 1.1. Lintasan berjarak 2

Misalkan $x=u_{i, j}$ dan $y=v_{i, j+2}$ dengan $i \in[1, t]$, dan $j \in[1,2]$. Terdapat lintasan pelangi $x$ ke $y$ yaitu $u_{i, j}, u_{i, j+1}, v_{i, j+2}$.

Kasus 2. Untuk $4 \leq n \leq 6$

Subkasus 2.1. Lintasan berjarak 2

1. Misalkan $x=u_{i, j}$ dan $y=v$ dengan $i \in[1, t]$ dan $j \in[1, n-1]$. Terdapat lintasan pelangi $x$ ke $y$ yaitu $u_{i, j}, v_{i, j}, v$.

2. Misalkan $x=u_{i, j}$ dan $y=u_{i, j+2}$ dengan $i \in[1, t]$ dan $j \in[1, n-3]$. Terdapat lintasan pelangi $x$ ke $y$ yaitu $u_{i, j}, u_{i, j+1}, u_{i, j+2}$.

3. Misalkan $x=v_{i, j}$ dan $y=v_{i, j+2}$ dengan $i \in[1, t]$ dan $j \in[1, n-2]$. Terdapat lintasan pelangi $x$ ke $y$ yaitu $v_{i, j}, v_{i, j+1}, v_{i, j+2}$.

4. Misalkan $x=v_{i, j}$ dan $y=v_{i, l}$ dengan $i \in[1, t], j \in[1, n-3]$ dan $l \in[4, n]$. Terdapat lintasan pelangi $x$ ke $y$ yaitu $v_{i, j}, v, v_{i, l}$.

5. Misalkan $x=v_{i, j}$ dan $y=v_{k, l}$ dengan $i \in[1, t-1], j, l \in[1, n]$ dan $k \in[i+1, t]$. Terdapat lintasan pelangi $x$ ke $y$ yaitu $v_{i, j}, v, v_{k, l}$.

6. Misalkan $x=v_{i, j}$ dan $y=u_{i, j+1}$ dengan $i \in[1, t]$, dan $j \in[1, n-2]$. Terdapat lintasan pelangi $x$ ke $y$ yaitu $v_{i, j}, v_{i, j+1}, u_{i, j+1}$.

Subkasus 2.2. Lintasan berjarak 3

1. Misalkan $x=u_{i, j}$ dan $y=v_{i, l}$ dengan $i \in[1, t], j \in[1, n-3]$, dan $l \in[4, n]$. Terdapat lintasan pelangi $x$ ke $y$ yaitu $u_{i, j}, v_{i, j+1}, v, v_{i, l}$.

2. Misalkan $x=v_{i, j}$ dan $y=u_{i, l}$ dengan $i \in[1, t], j \in[1, n-3]$, dan $l \in[3, n-1]$. Terdapat lintasan pelangi $x$ ke $y$ yaitu $v_{i, j}, v, v_{i, l+1}, u_{i, l}$.

3. Misalkan $x=u_{i, j}$ dan $y=v_{k, l}$ dengan $i \in[1, t-1], j \in[1, n-1], k \in[i+1, t]$, dan $l \in[1, n]$. Terdapat lintasan pelangi $x$ ke $y$ yaitu $u_{i, j}, v_{i, j}, v, v_{k, l}$.

4. Misalkan $x=v_{i, j}$ dan $y=u_{k, l}$ dengan $i \in[1, t-1], j \in[1, n], k \in[i+1, t]$, dan $l \in[1, n-1]$. Terdapat lintasan pelangi $x$ ke $y$ yaitu $v_{i, j}, v, v_{k, l}, u_{k, l}$. 
Subkasus 2.3. Lintasan berjarak 4

Misalkan $x=u_{i, j}$ dan $y=u_{k, l}$ dengan $i \in[1, t-1], j, l \in[1, n-1]$, dan $k \in[i+1, t]$. Terdapat lintasan pelangi $x$ ke $y$ yaitu $u_{i, j}, v_{i, j}, v, v_{k, l}, u_{k, l}$.

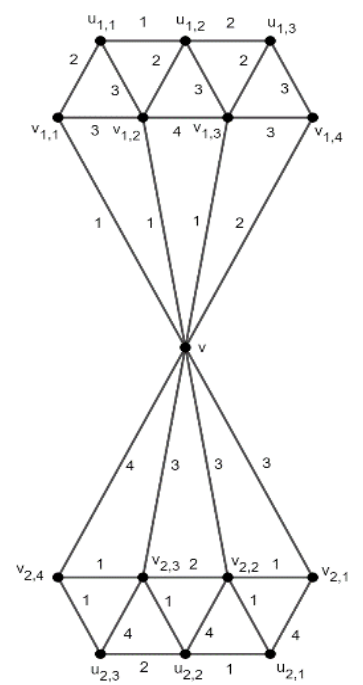

Gambar 2. Pewarnaan Pelangi $\operatorname{Amal}\left(\mathrm{Br}_{4}, v, 2\right)$

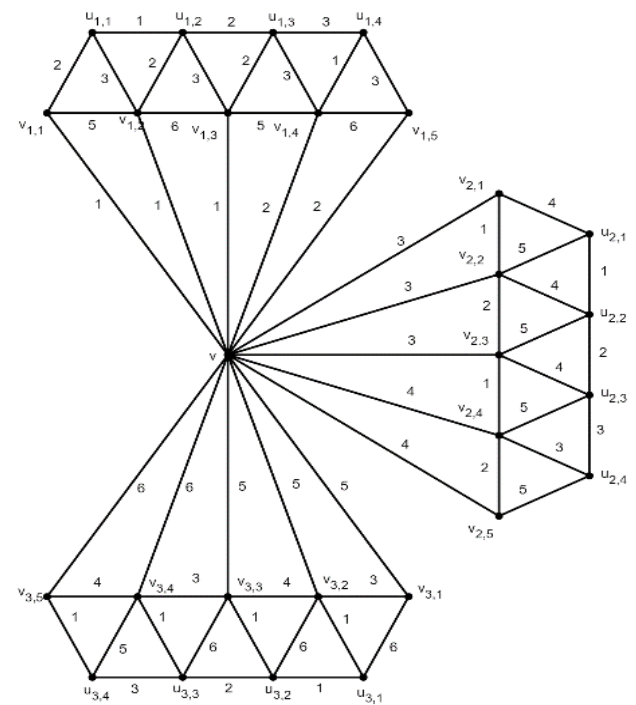

Gambar 3. Pewarnaan Pelangi $\operatorname{Amal}\left(B r_{5}, v, 3\right)$

Kasus 3. Untuk $n=5$ dan $n=6$

Subkasus 3.1. Lintasan berjarak 2

Subkasus 3.1. Lintasan berjarak 2

Misalkan $x=u_{i, j}$ dan $y=v_{i, j+2}$ dengan $i \in[1, t]$, dan $j \in[1, n-2]$. Terdapat lintasan pelangi $x$ ke $y$ yaitu $u_{i, j}, v_{i, j+1}, v_{i, j+2}$.

Subkasus 3.1. Lintasan berjarak 3

Misalkan $x=u_{i, j}$ dan $y=u_{i, j+3}$ dengan $i \in[1, t]$ dan $j \in[1, n-4]$. Terdapat lintasan pelangi $x$ ke $y$ yaitu $u_{i, j}, u_{i, j+1}, u_{i, j+2}, u_{i, j+3}$.

Kasus 4. Untuk $n=6$

Subkasus 4.1. Lintasan berjarak 4

Misalkan $x=u_{i, 1}$ dan $y=u_{i, 5}$ dengan $i \in[1, t]$. Terdapat lintasan pelangi $x$ ke $y$ yaitu $u_{i, 1}, u_{i, 2}, u_{i, 3}, u_{i, 4}, u_{i, 5}$. 


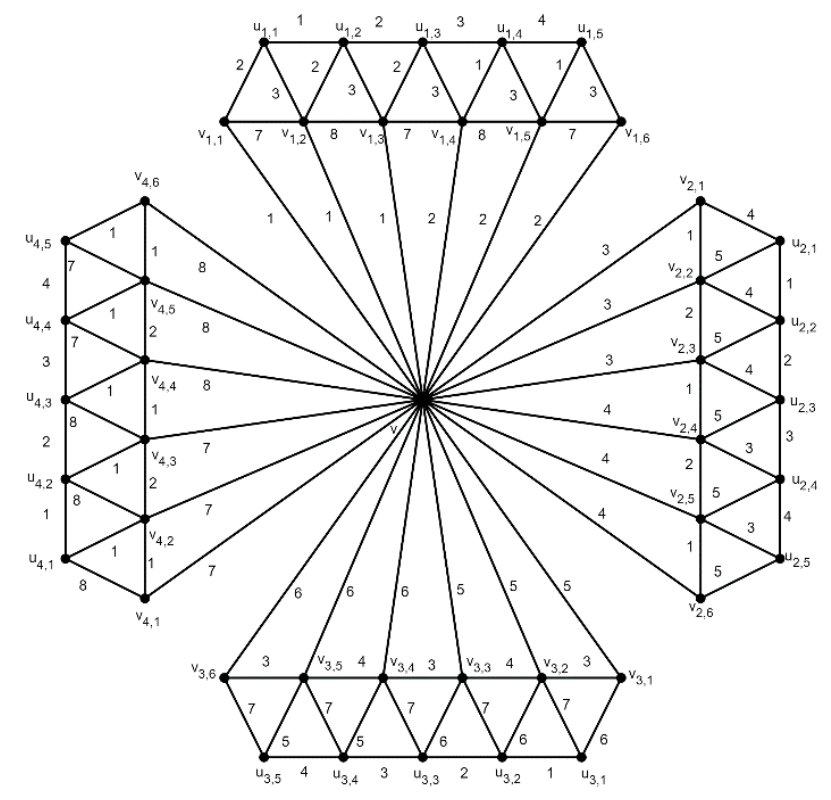

Gambar 4. Pewarnaan Pelangi $\operatorname{Amal}\left(B r_{6}, v, 4\right)$

\section{Kesimpulan}

Dari pembahasan diatas maka diperoleh bilangan terhubung pelangi pada amalgamasi graf berlian adalah :

$$
\operatorname{rc}\left(\operatorname{Amal}\left(B r_{n}, v, t\right)\right)=2 t \text {. }
$$

Penelitian selanjutnya dapat dilanjutkan untuk $n \geq 6$.

\section{Referensi}

[1] R. Munir, Matematika Disktrit, 3rd ed. Bandung: Informatika Bandung, 2010.

[2] J. L. Gross, "Genus distribution of graph amalgamations: Self-pasting at root-vertices," Australas. J. Comb., vol. 49, pp. 19-38, 2011.

[3] G. Chartrand, D. Erwin, P. Zhang, and M. Bohemica, "Mathematica Bohemica Terms of use:," vol. 127, no. 1,2008 .

[4] M. A. Shulhany and A. N. M. Salman, "Bilangan Terhubung Pelangi Graf Berlian," 2015. 